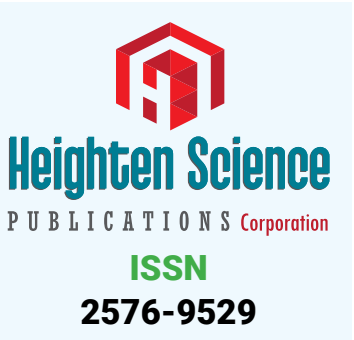

*Address for Correspondence: Dr. Bashir M. Matata, Liverpool Heart \& Chest Hospital NHS Trust, Thomas Drive, Liverpool, L14 3PE, UK, Tel: +441516001380; Fax: +441516001647; Email: matata_bashir@hotmail.com

Submitted: 02 February 2017

Approved: 22 February 2017

Published: 27 February 2017

Copyright: @ 2017 Matata BM, et al. This is an open access article distributed under the Creative Commons Attribution License, which permits unrestricted use, distribution, and reproduction in any medium, provided the original work is properly cited.

Keywords: Intraoperative hemofiltration; Freedom from death; Continuous Venovenous Hemofiltration; Risk-adjusted outcomes

\section{The Risk-Adjusted Impact of Intraoperative Hemofiltration on Real-World Outcomes of Patients Undergoing Cardiac Surgery}

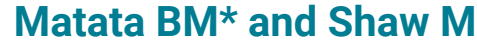 \\ Liverpool Heart \& Chest Hospital NHS Trust, Liverpool, United Kingdom
}

\section{ABSTRACT}

Objectives: The role of perioperative hemofiltration (HF) in adult patients with impaired renal function undergoing cardiac surgery is controversial. There are suggestions that it may be beneficial for high risk patients undergoing prolonged cardiopulmonary bypass (CPB) surgery. However, long term outcomes in coronary artery bypass graft (CABG) surgery patients have not been investigated.

Methods: To address this we retrospectively followed 7620 patients who underwent CABG between April 2001 and March 2006. Logistic regression was used to risk adjust in-hospital outcomes. Cox proportional hazards analysis was used to risk adjust Kaplan-Meier freedom from death curves. Outcomes were adjusted for American Heart Association and American College of College of Cardiology recommended variables.

Results: 113 patients had intraoperative HF, 38 had postoperative HF and control group of 7006 that had no HF. After adjusting for differences in case-mix, patients with preoperative kidney disease who received postoperative HF proportionately had significantly higher rates of hospital deaths as compared with intraoperative HF patients. In addition, 5-year follow-up risk-adjusted freedom from death indicated significant differences between intraoperative HF group and postoperative HF patients.

Conclusions: These findings support the hypothesis that after adjusting for differences in case mixes, the use of intraoperative hemofiltration may offer superior short term clinical outcomes and longer-term survival benefits for patients with preoperative kidney disease.

\section{INTRODUCTION}

Cardiopulmonary bypass is known to adversely impact upon perioperative renal function in particular for individuals with diabetes mellitus or an existing renal impairment [1]. Renal injury may occur resulting in acute kidney injury (AKI) which is the standard term for an abrupt and sustained decrease in renal function resulting in the retention of nitrogenous (urea and creatinine) and non-nitrogenous waste products. Depending on the severity and duration of the renal dysfunction, this accumulation is accompanied by metabolic disturbances, such as metabolic acidosis and hyperkalaemia, changes in body fluid balance, and effects on many other organ systems. Definitions of AKI have varied from the severe (i.e., that require dialysis) to the slight increases in serum creatinine concentration by $44 \cdot 2 \mu \mathrm{mol} / \mathrm{L}$ [2]. Severe AKI, defined as renal failure that requires renal replacement therapy is a major complication of cardiac surgery with an associated mortality of $60-100 \%$ when treated with standard hemodialysis [3]. More recently, continuous renal replacement techniques have been introduced, which circumvent the hemodialysis instability associated with intermittent hemodialysis and its limited ability to control the patient's volume state [4]. One such form of continuous renal replacement therapy is continuous venovenous hemodialysis (CVVH) that has

How to cite this article: Matata BM, Shaw M. The Risk-Adjusted Impact of Intraoperative Hemofiltration on Real-World Outcomes of Patients Undergoing Cardiac Surgery. J Clini Nephrol. 2017; 1: 001-010. https://doi.org/10.29328/journal.jcn.1001001 
been shown to substantially facilitate improved care of patients with severe AKI after cardiac operations when used early and intensively [5].

Hemofiltration was introduced in the 1980s for CPB management [6-9], and has been shown in pediatric cardiac surgery to be effective at regulating hemostasis, removal of cytokines and complement components [10]. Similarly, in adults zerobalance hemofiltration was shown to be effective at removing inflammatory mediators during СРВ $[10,11]$. In addition, one recen.t prospective, randomized double-blind trial demonstrated that hemofiltration but not steroids results in earlier tracheal extubation following CPB [12]. Initially hemofiltration was intended to correct the accumulation of extravascular water during or immediately following the surgical procedure. Several new benefits have been identified, such as the reduction of postoperative blood loss and immediate improvement in hemodynamic $[13,14]$.

In addition, recent evidence has shown that mild renal dysfunction is a predictor of outcomes in terms of in-hospital mortality, morbidity, and midterm survival in patients undergoing coronary artery bypass graft" (CABG) surgery [15]. Since hemofiltration is well tolerated in patients with compromised circulatory status this technique has become useful in the postoperative period for treating patients with acute renal failure. Indeed, early and aggressive continuous venovenous hemofiltration (CVVH) has been associated with better than predicted survival in severe postoperative AKI [16]. However it is still unknown as to whether real-world outcomes of cardiac operations incorporating intraoperative hemofiltration as applied during cardiopulmonary bypass surgery are markedly different from those with postoperative hemofiltration initiated in intensive care units or wards. The objective of this study was to analyse real-world data to assess whether outcomes differ for patients with preoperative kidney disease treated with hemofiltration modalities either during CPB or 1-2 days after coronary artery bypass graft (CABG)" to "CABG.

\section{MATERIALS AND METHODS}

\section{Patients}

We retrospectively followed 7620 patients who underwent on-pump first-time isolated cardiac bypass graft surgery between April 2001 and March 2006. All data were collected (Table 1) during in-patient admission as part of the routine clinical practice as previously described [17]. In-hospital mortality was defined as deaths within the same hospital admission regardless of cause or within 30 days of hospital

\begin{tabular}{|c|c|c|c|c|}
\hline & $\begin{array}{c}\text { Non-HF Group } \\
(n=7006)\end{array}$ & $\begin{array}{c}\text { Intra-Op } \\
\text { HF Group }(n=112)\end{array}$ & $\begin{array}{l}\text { Post-Op HF Group } \\
(n=38)\end{array}$ & $\mathbf{P}$ \\
\hline Age at Operation (years) & 65.2 & 62.3 & 68.9 & 0.04 \\
\hline Female (\%) & 26.9 & 39.3 & 26.3 & 0.01 \\
\hline Body mass index $\left(\mathrm{kg} / \mathrm{m}^{2}\right)$ & 27.8 & 27.7 & 27.1 & 0.29 \\
\hline Diabetes (\%) & 19.1 & 20.5 & 47.4 & $<0.01$ \\
\hline PVD (\%) & 11.2 & 5.4 & 18.4 & 0.05 \\
\hline Cerebrovascular disease (\%) & 9.4 & 7.1 & 7.9 & 0.65 \\
\hline Respiratory disease (\%) & 36.5 & 45.5 & 50.0 & 0.03 \\
\hline Preoperative renal dysfunction (\%) & 4.2 & 38.4 & 100.0 & $<0.01$ \\
\hline Hypertension (\%) & 57.9 & 50.0 & 67.2 & 0.20 \\
\hline Current smoker (\%) & 14.3 & 19.6 & 13.2 & 0.27 \\
\hline Triple-vessel disease (\%) & 54.9 & 40.2 & 71.1 & $<0.01$ \\
\hline LMS stenosis $>50 \%(\%)$ & 16.2 & 12.5 & 21.1 & 0.41 \\
\hline Ejection fraction <30\% (\%) & 7.6 & 8.9 & 31.6 & $<0.01$ \\
\hline Previous cardiac surgery (\%) & 4.2 & 13.4 & 7.9 & $<0.01$ \\
\hline Non-elective surgery (\%) & 14.9 & 41.1 & 52.6 & $<0.01$ \\
\hline Logistic EuroSCORE & 6.7 & 16.5 & 26.6 & $<0.01$ \\
\hline ICU length of stay (days) & 2.4 & 7.1 & 13.0 & $<0.01$ \\
\hline Hospital stay (days) & 10.8 & 17.9 & 24.3 & $<0.01$ \\
\hline
\end{tabular}

LMS: left main stem; ICU: intensive care unit; PVD: peripheral vascular disease. 
discharge. Postoperative stroke was defined as a new focal neurological deficit and comatose states' occurring postoperatively that persisted for 24 hours after its onset and was noted before discharge. Transient confused states and temporary intellectual impairment were not included. Postoperative myocardial infarction was defined as unequivocal ECG changes, elevation of cardiac enzyme(s) to 3 times upper limit of creatinine kinase (CKMB) and above twice the upper limit of normal or elevated troponin (T/I), and chest pain typical of ischemia lasting for more than 20 minutes. The European Risk Stratification Score System (EuroSCORE) was used to assess risk associated with cardiac surgery [18].

Patients with renal dysfunction were described as those with an estimated glomerular filtration rate (eGFR) $<60 \mathrm{~mL} /$ minute $/ 1.73 \mathrm{~m}^{2}$ that has persisted for at least 3 months before the date of surgery. We stratified patients into 3 groups: (1) patients treated with intraoperative hemofiltration $(\mathrm{n}=112)$ during cardiopulmonary bypass; (2) patients treated with postoperative hemofiltration ( $n=38)$; (3) a control group without hemofiltration use $(n=7006)$. Patients with preoperative dialysis dependent renal insufficiency were excluded from further analysis.

Intraoperative hemofiltration was applied for either secondary renal impairment or correction of fluid retention due to cardiac failure/excessive hemodilution. Standard intraoperative hemofiltration involves connecting a parallel circuit to the cardiopulmonary bypass via hollow fibre filters (Polysulfone PS, Hospal Lyon, France). Blood flow rates were maintained at $300-500 \mathrm{ml} / \mathrm{min}$ (about $10 \%$ of the pump output) with a transmembrane pressure of about $300 \mathrm{~mm} \mathrm{Hg}$.

Cases of severe AKI were identified postoperatively and treated with continuous venovenous hemofiltration (CVVH). AKI was as previously defined by the KIDGO consensus conference $[19,20]$. The technique of CVVH involved a double lumen catheter connected to a blood pump, through which blood was pumped into a module at flow rates of 200 to $250 \mathrm{~mL} / \mathrm{m}$ with an intravenous pump controlling the ultrafiltration rate at $2 \mathrm{~L} / \mathrm{h}$. The module was also equipped with pressure alarms and an air bubble trap. Standard Polysulfone PS filters were used in all patients. Anticoagulation of the circuit was performed in accordance with local clinical practice governed by duration of hemofiltration. Replacement fluids were administered at the pre-filter stage with rates chosen to suit the desired fluid therapy goals.

\section{Patient follow-up}

The patients were followed up through a national tracing service using patient's name, National Health Service unique number and date of birth, gender, and postcode.

\section{Study endpoints}

The primary endpoint was the risk-adjusted freedom from death within the 5-year study period. Secondary outcomes include risk-adjusted in-hospital death, atrial fibrillation, myocardial infarction, stroke, re-operation for bleeding, and surgical wound infections.

\section{Statistical analyses}

Due to non-normality of data, continuous variables are shown as median with 25th and 75th percentiles. Categorical variables are shown as a percentage. Comparisons were made with Kruskal-Wallis tests and Chi-square tests as appropriate. Logistic regression was used to risk adjust in-hospital outcomes for differences in patient and disease characteristics [21]. Deaths occurring as a function of time were described using the product limit methodology of Kaplan and Meier [22]. Cox proportional hazards analysis was used to calculate adjusted hazard ratios (HR) and to risk adjust the Kaplan-Meier survival curves [23]. Logistic EuroSCORE [18] was used for risk 
adjustment. This approach aims to balance out patient preoperative characteristics by incorporating a commonly used cardiac surgery risk scoring method. In all cases a p value $<0.05$ was considered significant. All statistical analysis was performed with SAS for Windows Version 8.2.

\section{RESULTS}

\section{In-hospital outcomes}

A total of 113 patients had intraoperative HF, 38 had postoperative HF and 7006 had no HF. Tables 1 and 2, shows patient's preoperative characteristics and in-hospital outcomes. In the unmatched data (Table 2), we observed increased in-hospital death, and re-operation for bleeding outcomes in both the HF groups as compared to the control group without HF. More volume was removed from the postoperative haemofiltration group (Table 2). Interestingly, all the patients in the postoperative HF group had preoperative renal impairment and that $97 \%$ of these patients went on to developed acute kidney injury that necessitated hemofiltration in intensive care unit.

In contrast, $38 \%$ of the patients on intraoperative hemofiltration had preoperative renal impairment and 27\% developed perioperative acute kidney injury. As shown on table 3, only $39.5 \%$ of patients with preoperative renal dysfunction that undergone intraoperative HF had AKI compared with $33.5 \%$ of those in the group that had no preoperative kidney impairment. This compares favourable with patients that had the conventional delayed postoperative CVVH where all patients who had preoperative kidney disease suffered AKI except one.

The adjusted odds ratios (OR) for in hospital outcomes (Table 4) indicated that in both intraoperative and postoperative HF groups there was no association between the use of $\mathrm{HF}$ with in hospital strokes, re-operation for bleeding, myocardial infarction and surgical wound infections. In contrast, a strong association was shown with inhospital death for intraoperative HF (OR 2.8, CI 1.5-5.1, P<0.001) and more so in the postoperative HF group (OR 12.1, CI 5.7-25.6, $\mathrm{P}<0.001$ ). Atrial fibrillation was also significantly associated with postoperative HF group but not the intraoperative HF group.

Table 2: Unadjusted in-hospital outcomes.

\begin{tabular}{|c|c|c|c|c|}
\hline & $\begin{array}{c}\text { Non-HF Control Group } \\
(n=7006)\end{array}$ & $\begin{array}{c}\text { Intra-Op } \\
\text { HF Group }(n=112)\end{array}$ & $\begin{array}{l}\text { Post-Op HF Group } \\
(n=38)\end{array}$ & $\mathbf{P}$ \\
\hline Death (\%) & 3.4 & 16.1 & 50.0 & $<0.01$ \\
\hline Stroke (\%) & 2.2 & 1.8 & 2.6 & 0.94 \\
\hline Myocardial Infarction (\%) & 1.7 & 2.7 & 0.0 & 0.51 \\
\hline Atrial fibrillation (\%) & 27.8 & 27.7 & 50.0 & $<0.01$ \\
\hline Re-operation for bleeding (\%) & 5.0 & 10.7 & 15.8 & $<0.01$ \\
\hline Acute Kidney Injury (\%) & 6.4 & 23.2 & 97.4 & $<0.01$ \\
\hline Surgical wound infection (\%) & 3.5 & 5.4 & 7.9 & 0.21 \\
\hline Volume removed $(\mathrm{mL})$ & - & $2000(800-7000)$ & $8200(7075-14500)$ & 0.04 \\
\hline Balance $(\mathrm{mL})$ & - & $0(0-0)$ & $-875(-2325-4250)$ & 0.84 \\
\hline Creatinine $(\mu \mathrm{mol} / \mathrm{L})$ & - & 291 (203-739) & $230(201-273)$ & 0.35 \\
\hline
\end{tabular}

Table 3: Incidences of preoperative renal dysfunction and corresponding AKI rates.

\begin{tabular}{|c|c|c|c|}
\hline & No HF & Intra-Op HF & Post-Op HF \\
\hline Preoperative renal dysfunction & $296 / 7006(4.2 \%)$ & $43 / 112(38.4 \%)$ & $38 / 38(100 \%)$ \\
\hline Post-operative AKI patients & $99 / 296(33.5 \%)$ & $17 / 43(39.5 \%)$ & $37 / 38(97.4 \%)$ \\
\hline
\end{tabular}




\begin{tabular}{|c|c|c|c|c|c|c|}
\hline & $\begin{array}{l}\text { Intra Op HF } \\
\text { Odds Ratio }\end{array}$ & $95 \% \mathrm{Cl}$ & p Value & $\begin{array}{l}\text { Post Op HF } \\
\text { Odds Ratio }\end{array}$ & $95 \% \mathrm{Cl}$ & p Value \\
\hline \multicolumn{7}{|c|}{ In-Hospital Mortality } \\
\hline Crude & 5.5 & $3.3-9.2$ & $<0.001$ & 28.7 & $15.0-54.9$ & $<0.001$ \\
\hline Adjusted* & 2.8 & $1.5-5.1$ & $<0.001$ & 12.1 & $5.7-25.6$ & $<0.001$ \\
\hline \multicolumn{7}{|l|}{ Stroke } \\
\hline Crude & 0.8 & $0.2-3.3$ & 0.77 & 1.2 & $0.2-8.9$ & 0.85 \\
\hline Adjusted* & 0.4 & $0.09-1.6$ & 0.19 & 0.4 & $0.05-2.9$ & 0.34 \\
\hline \multicolumn{7}{|c|}{ Myocardial Infarction } \\
\hline Crude & 1.6 & $0.5-5.2$ & 0.40 & - & - & - \\
\hline Adjusted* & 1.3 & $0.4-4.2$ & 0.69 & - & - & - \\
\hline \multicolumn{7}{|c|}{ Atrial Fibrillation } \\
\hline Crude & 1.0 & $0.7-1.5$ & 0.98 & 2.6 & $1.4-4.9$ & 0.002 \\
\hline Adjusted* & 0.9 & $0.6-1.4$ & 0.69 & 2.2 & $1.1-4.2$ & 0.02 \\
\hline \multicolumn{7}{|c|}{ Re-operation for bleeding } \\
\hline Crude & 2.3 & $1.2-4.2$ & 0.006 & 3.6 & $1.5-8.6$ & 0.002 \\
\hline Adjusted* & 1.8 & $0.9-3.3$ & 0.08 & 2.0 & $0.8-5.1$ & 0.13 \\
\hline \multicolumn{7}{|c|}{ Acute kidney injury } \\
\hline Crude & 4.4 & $2.8-6.9$ & $<0.001$ & 541.6 & 74.1->999 & $<0.001$ \\
\hline Adjusted* & 2.6 & $1.6-4.3$ & $<0.001$ & 340.6 & $46.0->999$ & $<0.001$ \\
\hline \multicolumn{7}{|c|}{ Surgical wound infection } \\
\hline Crude & 1.5 & $0.7-3.5$ & 0.30 & 2.3 & $0.7-7.6$ & 0.15 \\
\hline Adjusted* & 1.2 & $0.5-2.9$ & 0.63 & 1.5 & $0.5-5.2$ & 0.50 \\
\hline
\end{tabular}

\section{Freedom from death analysis}

Freedom from death curves are shown in figure 1. After adjusting for differences in a number of confounding factors (Figure 2), there was a significantly higher mortality during the follow-up period for the postoperative HF patients as compared with the intraoperative HF group.

\section{DISCUSSION}

The application of hemofiltration before and after CABG surgery is very common for a number of indications including fluid overload and preoperative kidney impairment. Studies [24] have shown that up to $10 \%$ of patients sustain renal dysfunction due to kidney injury induced by CPB during CABG surgery [25,26]. Karkouti et al. [27], also demonstrated that $\mathrm{CPB}$ was associated with a $33.6 \%$ prevalence of postoperative acute kidney injury (AKI), which was associated independently with a greater than 4 -fold increase in the odds of death. The findings are consistent with our observations of $6.4 \%$ postoperative AKI rates for patients with no history of preoperative kidney disease and that these rates increase significantly (3.5-15 fold) for patients with a history of preoperative kidney disease irrespective of the type of renal replacement intervention used. These findings are in agreement with previous studies [15] that also demonstrated that preoperative mild kidney disease was highly predictive of both AKI and in-hospital deaths [15].

Mechanisms related to the occurrence of AKI in these patients is however still uncertain. Several studies [28-30] have previously demonstrated that renal injury sustained during cardiac surgery may be mechanistically related to pre-existing renal dysfunction, diabetes mellitus, ventricular dysfunction, older age, hypertension, microembolic and macroembolic processes, inflammatory mediators, prolonged CPB time, sensitivity to sympatheticstimulation, and perturbation in renovascular resistance and flow. Indeed findings from our study suggest that when data are corrected for pre-existing renal dysfunction, diabetes mellitus, ventricular dysfunction, older age, hypertension, the risk of AKI is significantly reduced for patients on intraoperative $\mathrm{HF}$, suggesting that multiple comorbidities contribute to incidents of AKI. Interestingly, the incidents of AKI in patients with preoperative kidney injury were comparable to those 

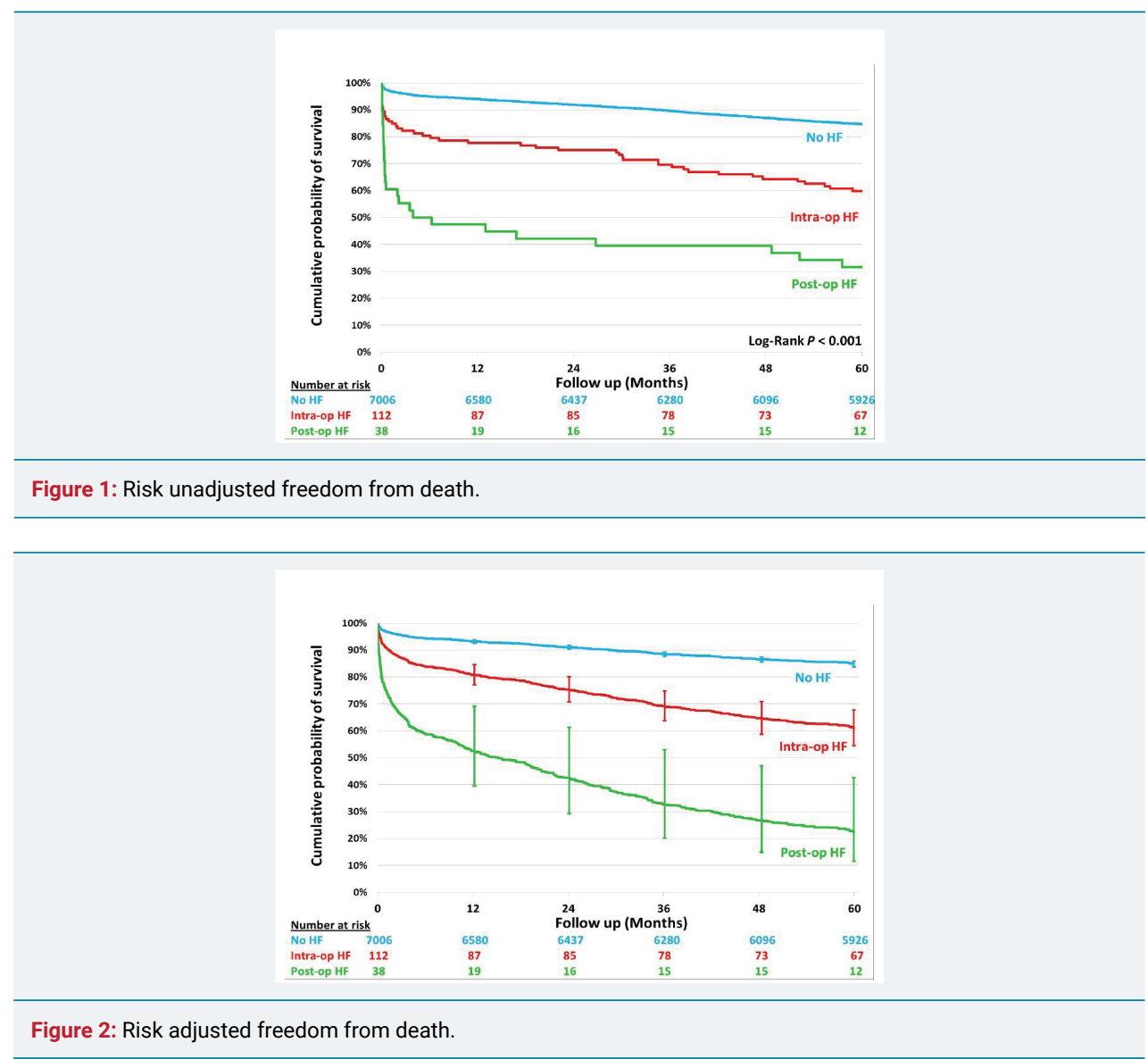

without when intraoperative HF is given. This may suggest that intraoperative HF may protect patients from CPB-induced injury.

Other authors [31] have also demonstrated that the occurrence of postoperative mild to moderate acute kidney injury (AKI) was associated with a mortality rate of $10 \%$ to $20 \%$, findings that are consistent with results from our study. Interestingly, AKI incidents in this study were associated with even much higher in-hospital mortality rates $(50 \%)$ despite the application of postoperative CVVH. When the results are corrected for preoperative chronic kidney disease and other risk factors, the evidence also suggests that preoperative kidney disease is the single most significant risk factor for in-hospital mortality irrespective of renal support treatment modalities.

Currently, there is a lack of consensus on indications for and timing of initiation of renal support for patients with preexisting renal impairment or those at risk of AKI in the perioperative period. Some studies have shown that postoperative HF improves outcomes if initiated early [32-36]. In contrast, others such as Bouman and co-workers in 2003 [37] studied the effects of the initiation time of continuous venovenous hemofiltration on patients with circulatory and respiratory insufficiency leading to oliguric AKI. The authors observed that recovery of renal function was not improved by using high ultrafiltrate volumes or by early initiation of hemofiltration. In addition, other randomised studies failed to demonstrate that intensity/duration of renal replacement therapy could improve outcomes [38,39]. Issues remain regarding the proper definition of AKI $[19,20]$. While there is an unanimous agreement that renal complication severely impact patient outcome, specific aspects of management, including the method of renal replacement therapy, i.e. dialysis based on the diffusion principle or hemofiltration (based on convection); the dose of renal replacement therapy (Urea KT/V for dialysis vs. hemofiltration flow ( $\mathrm{ml} / \mathrm{kg} /$ hour)), and the timing (early vs. late) of renal replacement therapy are all controversial. Even after a consensus 
definition was put forward [the R.I.F.L.E classification: 2nd Consensus Conference, ADQI Group [40-42], there is still great uncertainty as what is the best course of action when treatment decisions have to be made specifically aimed at patients with preexisting renal impairment. Existing evidence would suggest that even slightly elevated serum creatinine predicts AKI requiring hemofiltration after cardiac surgery [43]. Despite the limitations, our study is the first to show that in high risk category of patients with pre-existing renal impairment, hemofiltration during cardiopulmonary bypass can minimise incidences of postoperative AKI or has survival benefits.

Based on the observation from our study that patients with high preoperative risk scores (EuroSCORE >16.1) are at increased risk of further renal impairment we hypothesize that it is these types of patients who could derive significant benefits from intraoperative hemofiltration. Indeed our most recent randomised controlled trial on intraoperative hemofiltration during cardiac surgery for patients with preoperative chronic kidney disease demonstrated superior outcomes as compared with treatment as usual. This is in terms of significant reduction in rates of pulmonary infections and in-hospital deaths compared with a control usual care group without the use of intraoperative hemofiltration [44].

The randomised trial [44] appear to support the findings from this real-world study setting that after adjusting for case mixes intraoperative hemofiltration is associated with more favourable short term outcomes such as in-hospital death and reduced risk of atrial fibrillation as compared with equivalent patients that received the traditional delayed postoperative hemofiltration care.

The underlying mechanisms for these benefits have yet to be elucidated. It is possible that the benefits of intraoperative hemofiltration (conventional or modified ultrafiltration) can be explained by the elimination of inflammatory mediators during the metabolic stressful period of coronary bypass, as demonstrated in studies before [6-10]. In addition, there is also evidence to suggest that intraoperative hemofiltration reduces levels of $\mathrm{S} 100 \mathrm{~b}$ release and cognitive dysfunction [11], resulting in an earlier tracheal extubation following cardiopulmonary bypass [12]. In other studies it has also been shown that intraoperative hemofiltration may reduce the requirement for post-operative blood transfusion, also increase BP and cardiac index immediately after hemofiltration [45].

In conclusion, findings from this study support the hypothesis that the use of intraoperative hemofiltration may offer short term clinical benefits and improve longer-term survival for patients with preoperative kidney disease. In contrast, the delayed use of postoperative hemofiltration on patients with known preoperative kidney impairment does not significantly impact occurrence of AKI and the impact of AKI on survival. It is with this reasoning and evidence from other studies [46-48] that we hypothesize that for patients with preoperative kidney disease routine application of intraoperative haemofiltration or early CVVH rather than the traditional delayed CVVH (which is commonly started 1-3 days after CABG in response to mostly oliguria symptoms and electrolytes imbalance) may improve outcomes of these vulnerable patients. The recent introduction of hemodialfiltration techniques incorporating citrate-based regional anticoagulation systems soon after CPB may be a game changer for patients with preoperative kidney disease in routine clinical practice [49].

\section{STUDY LIMITATIONS}

Although our study included a large sample of patients undergoing coronary artery bypass surgery, it was not a prospective randomised trial, and therefore had a number of limitations. For example, patients who received HF on bypass were likely to have had less severe renal impairment and a lower EuroSCORE, and therefore this might impact upon the results giving the Intra-Op HF Group a better outcome because they 
were going to do well regardless. Our study, however, considered three unselected study groups of patients on the basis of use and timing of hemofiltration and therefore provides an insight into real practice. In addition, the follow-up data obtained via the National Institute of Statistics only provided us with knowledge of the survival status without the cause of death or differentiation between cardiovascular or other cause of death. We also do not have data on the underlying pathophysiology of renal dysfunction in the patients included in the study. The findings however suggest that a well-designed randomised study would offer a better evaluation of the treatment strategies for this group of patients.

\section{REFERENCES}

1. Burns KE, Chu MW, Novick RJ, Fox SA, Gallo K, et al. Perioperative N-acetylcysteine to prevent renal dysfunction in high-risk patients undergoing CABG surgery: a randomized controlled trial. JAMA. 2005; 294: 342-350. Ref.: https://goo.gl/duU8xm

2. Fischer UM, Weissenberger WK, Warters RD, Geissler HJ, Allen SJ, et al. Impact of cardiopulmonary bypass management on postcardiac surgery renal function. Perfusion. 2002; 17: 401-406. Ref.: https://goo.gl/BzqWZF

3. Lange HW, Aeppli DM, Brown DC. Survival of patients with acute renal failure requiring dialysis after open-heart surgery: early prognostic indicators. Am Heart J. 1987; 113: 1138-1143.

4. Coraim F, Wolner E. Management of cardiac surgery patients with continuous arteriovenous hemofiltration. Crit Care Med 1986; 14: 714-718. Ref.: https://goo.gl/7pTDEV

5. Draaisma AM, Hazekamp MG, Frank M, Anes N, Schoof PH, et al. Modified ultrafiltration after cardiopulmonary bypass in pediatric cardiac surgery. Ann Thorac Surg. 1997; 64: 521-525. Ref.: https://goo.gl/Qo9gQA

6. Hakim M, Wheeldon D, Bethune DW, Milstein BB, English TAH, et al. Haemodialysis and haemofiltration on cardiopulmonary bypass. Thorax. 1985; 40: 101-106. Ref.: https://goo.gl/I2juhw

7. Journois D. Hemofiltration during cardiopulmonary bypass. Kidney Int Suppl. 1998; 66: S174-S177. Ref.: https://goo.gl/P5I2IF

8. Journois D, Israel-Biet D, Pouard P, Rolland B, Silvester W, et al. High-volume, zero-balanced hemofiltration to reduce delayed inflammatory response to cardiopulmonary bypass in children. Anesthesiology. 1996; 85: 965-976. Ref.: https://goo.gl/V9Hpna

9. Journois $D$, Pouard $P$, Greeley WJ, Mauriat $P$, Vouhé $P$, et al. Hemofiltration during cardiopulmonary bypass in pediatric cardiac surgery. Effects on hemostasis, cytokines, and complement components. Anesthesiology. 1994; 81: 1181-119, discussion 26A-27A. Ref.: https://goo.gl/4liQGj

10. Tallman RD, Dumond $\mathrm{M}$, Brown $\mathrm{D}$. Inflammatory mediator removal by zero-balance ultrafiltration during cardiopulmonary bypass. Perfusion. 2002; 17: 111-115. Ref.: https://goo.gl/Wiloeb

11. de Baar M, Diephuis JC, Moons KG, Holtkamp J, Hijman R, et al. The effect of zero-balanced ultrafiltration during cardiopulmonary bypass on $\mathrm{S} 100 \mathrm{~b}$ release and cognitive function. Perfusion. 2003; 18: 9-14. Ref.: https://goo.gl/Drre3E

12. Oliver WC Jr, Nuttall GA, Orszulak TA, Bamlet WR, Abel MD, et al. Hemofiltration but not steroids results in earlier tracheal extubation following cardiopulmonary bypass: a prospective, randomized double-blind trial. Anesthesiology. 2004; 101: 327-339. Ref.: https://goo.gl/9ww1HA

13. Bogă M, Islamoğlu, Badak I, Cikirikçioğlu M, Bakalim T, et al. The effects of modified hemofiltration on inflammatory mediators and cardiac performance in coronary artery bypass grafting. Perfusion. 2000; 15: 143-150. Ref.: https://goo.gl/mHlrHN

14. Munakata M, Itaya H, Daitoku K, Ono Y. Remarkable improvement of hemodynamics by continuous hemodiafiltration in patients after operation for thoracic aortic dissection. Ann Thorac Cardiovasc Surg. 2005; 11: 277-280. Ref.: https://goo.gl/0HgLU4

15. Zakeri R, Freemantly N, Barnett V, Lipkin GW, Bonser RS, et al. Relation between mild renal dysfunction and outcomes after coronary artery bypass grafting. Circulation. 2005; 112: 1270-1275. Ref.: https://goo.gl/kvDwhZ

16. Bent P, Tan HK, Bellomo R, Buckmaster J, Doolan L, et al. Early and intensive continuous hemofiltration for severe renal failure after cardiac surgery. Ann Thorac Surg. 2001; 71: 832-837. Ref.: https://goo.gl/7GN5Dd 
17. Ashraf MN, Mortasawi A, Grayson AD, Oo AY. Effect of smoking status on mortality and morbidity following coronary artery bypass surgery. Thorac Cardiovasc Surg. 2004; 52: 1-6. Ref.: https://goo.gl/3lczwd

18. Nashef SA, Roques F, Michael P, Gauduchean E, Lemeshow S, et al. European system for cardiac operation risk evaluation (EuroSCORE). Eur J Cardiothoracic Surg. 1999; 16: 9-13. Ref.: https://goo.gl/GCSfNL

19. Eckardt KU, Kasiske BL. Kidney Disease: Improving Global Outcomes (KDIGO) Acute Kidney Injury Work Group. KDIGO Clinical Practice Guideline for Acute Kidney Injury. Kidney Inter Suppl. 2012; 2 1-38. Ref.: https://goo.gl/dPKzD6

20. Levey AS, deJong PE, Coresh J, El Nahas M, Astor BC, et al. The definition, classification and prognosis of chronic kidney disease: AKDIGO Controversies Conference report. Kidney Int. 2011; 80: 17-28. Ref.: https://goo.gl/2i6Cvo

21. Hosmer D, Lemeshow S. Applied logistic regression. New York, NY: John Wiley \& Sons Inc; 1989.

22. Kaplan EL, Meier P. Nonparametric estimation from incomplete observations. J Am Stat Assoc 1958; 53:547-581. Ref.: https://goo.gl/jzFygw

23. Cox DR. Regression models and life tables. J R Stat Soc. 1972; 34: 187-220. Ref.: https://goo.gl/HaJHJn

24. Mangano CM, Diamondstone LS, Ramsay JG, Aggarwal A, Herskowitz A, et al. Renal dysfunction after myocardial revascularization: risk factors, adverse outcomes, and hospital resource utilization. The Multicenter Study of Perioperative Ischemia Research Group. Ann Intern Med. 1998; 128: 194203. Ref.: https://goo.gl/ESYjwq

25. Anderson RJ, O'Brien M, MaWhinney S, VillaNueva CB, Moritz TE, et al. Mild renal failure is associated with adverse outcome after cardiac valve surgery. Am J Kidney Dis. 2000; 35: 1127-1134. Ref.: https://goo.gl/10UGxM

26. Mack MJ, Brown PP, Kugelmass AD, Battaglia SL, Tarkington LG, et al. Current status and outcomes of coronary revascularization 1999 to 2002: 148,396 surgical and percutaneous procedures. Ann Thorac Surg. 2004; 77: 761-766. Ref.: https://goo.gl/tmuqkc

27. Karkouti K, Wijeysundera DN, Yau TM, Callum JL, Cheng DC, et al. Acute kidney injury after cardiac surgery. Circulation. 2009; 119: 495-502. Ref.: https://goo.gl/1 byfml

28. Conlon PJ, Stafford-Smith M, White WD, Newman MF, King S, et al. Acute renal failure following cardiac surgery. Nephrol Dial Transplant. 1999; 14: 1158-1162. Ref.: https://goo.gl/RywW6f

29. Chertow GM, Lazarus JM, Christiansen CL, Cook EF, Hammermeister KE, et al. Preoperative renal risk stratification. Circulation. 1997; 95: 878-884. Ref.: https://goo.gl/fCHNs4

30. Page US, Washburn T. Using tracking data to find complications that physicians miss: the case of renal failure in cardiac surgery. Jt Comm J Qual Improv. 1997; 23: 511-520. Ref.: https://goo.gl/hHQJZy

31. Schwilk B, Wiedeck $H$, Stein B, Reinelt $H$, Treiber $H$, et al. Epidemiology of acute renal failure and outcome of haemofiltration in intensive care. Intensive Care Med. 1997; 23: 1204-1211. Ref.: https://goo.gl/JtRQv7

32. Elahi MM, Lim MY, Joseph RN, Dhannapuneni RR, Spyt TJ. Early hemofiltration improves survival in post-cardiotomy patients with acute renal failure. Eur J Cardiothorac Surg. 2004; 26: 1027-1031. Ref.: https://goo.gl/12EHYq

33. Bent P, Tan HK, Bellomo R, Buckmaster J, Doolan L, et al. Early and intensive continuous hemofiltration for severe renal failure after cardiac surgery. Ann Thorac Surg. 2001; 71: 832-837. Ref.: https://goo.gl/THhLQA

34. Gettings LG, Reynolds HN, Scalea T. Outcome in post-traumatic acute renal failure when continuous renal replacement therapy is applied early vs. late. Intensive Care Med. 1999; 25: 805-813. Ref.: https://goo.gl/v08zXL

35. Demirkilic U, Kuralay E, Yenicesu M, Caglar K, Oz BS, et al. Timing of replacement therapy for acute renal failure after cardiac surgery. J Card Surg. 2004; 19: 17-20. Ref.: https://goo.gl/7GM9VX

36. Luckraz H, Gravenor MB, George R, Taylor S, Williams A, et al. Long and short-term outcomes in patients requiring continuous renal replacement therapy post cardiopulmonary bypass. Eur $\mathrm{J}$ Cardiothorac Surg. 2005; 27: 906-909. Ref.: https://goo.gl/nTWH8H 
37. Bouman CS, Oudemans-Van Straaten HM, Tijssen JG, Zandstra DF, et al. Effects of early high-volume venovenous hemofiltration on survival and recovery of renal function in intensive care patients with acute renal failure: a prospective, randomised trial. Crit Care Med. 2002; 30: 2205-2211. Ref.: https://goo.gl/zhzEjl

38. Palevsky PM, Zhang JH, O'Connor TZ, Chertow GM, Crowley ST, et al. Intensity of renal support in critically ill patients with acute kidney injury. N Engl J Med. 2008; 359: 1-14. Ref.: https://goo.gl/V7hTZz

39. Tolwani AJ, Campbell RC, Stofan BS, Lai KR, Oster RA, et al. Standard versus high dose CVVHDF for ICU-related acute renal failure. J Am Soc Nephrol. 2008; 19: 1233-1238. Ref.: https://goo.gl/qsGm3K

40. Bellomo R, Ronco C, Kellum JA, Mehta RL, Palevsky P. Acute Dialysis Quality Initiative workgroup. Acute renal failure - definition, outcome measures, animal models, fluid therapy and information technology needs: the Second International Consensus Conference of the Acute Dialysis Quality Initiative (ADQI) Group. Crit Care. 2004; 8: R204-R212. Ref.: https://goo.gl/rjBD6v

41. Lameire N, Van Biesen W, Vanholder R. Acute renal failure. Lancet. 2005; 365: 417-430. Ref.: https://goo.gl//LeJyd

42. Ricci Z, Cruz D, Ronco C. The RIFLE criteria and mortality in acute kidney injury: A systemic review. Kidney Int. 2008; 73: 538-546. Ref.: https://goo.gl//pokvX

43. Kilo J, Margreiter JE, Ruttmann E, Laufer G, Bonatti JO. Slightly elevated serum creatinine predicts renal failure requiring hemofiltration after cardiac surgery. Heart Surg Forum. 2005; 8: 34-38. Ref.: https://goo.gl/AvDrKo

44. Matata B, Scawn N, Morgan M, Shirley S, Kemp I, et al. A single-centre randomised trial of intraoperative zero-balanced ultrafiltration during cardiopulmonary bypass for patients with impaired kidney function. J Cardiothorac Vasc Anesthesia. 2015; 29: 1236-1247. Ref.: https://goo.gl/ocNO2C

45. Das S, Dunning J. Is prophylactic haemofiltration during cardiopulmonary bypass of benefit during cardiac surgery? Interact Cardiovasc Thorac Surg. 2003; 2: 420-423. Ref.: https://goo.gl/YpaKRp

46. Elahi M, Asopa S, Pflueger A, Hakim N, Matata B. Acute kidney injury following cardiac surgery: Impact of early versus late haemofiltration on morbidity and mortality. Eur $\mathrm{J}$ Cardiothorac Surg. 2009; 35: 854-863. Ref.: https://goo.gl/u6NA3D

47. Bent P, Tan HK, Bellomo R, Buckmaster J, Doolan L, et al. Early and intensive continuous haemofiltration for severe renal failure after cardiac surgery. Ann Thorac Surg. 2000; 71: 832-837. Ref.: https://goo.gl/prQzg7

48. Karvellas CJ, Farhat MR, Sajjad I, Mogensen SS, Leung AA, et al. A comparison of early versus late initiation of renal replacement therapy in critically ill patients with acute kidney injury: a systematic review and meta-analysis. Crit Care. 2011; 15: R72. Ref.: https://goo.gl/eEWYVr

49. Oudemans-van Straaten HM, Ostermann M. Bench-to-bedside review: Citrate for continuous renal replacement therapy, from science to practice. Crit Care. 2012; 16: 249. Ref.: https://goo.gl/g0zUBN 